Article

\title{
Workplace Adaptations Promoting the Inclusion of Persons with Disabilities in Mainstream Employment: A Case-Study on Employers' Responses in Norway
}

\author{
Yuliya Kuznetsova ${ }^{1, *}$ and João Paulo Cerdeira Bento ${ }^{2}$ \\ ${ }^{1}$ NOVA Norwegian Social Research, Oslo Metropolitan University, 0130 Oslo, Norway; E-Mail: ykuznets2011@gmail.com \\ 2 Department of Economics, Management, Industrial Engineering and Tourism, University of Aveiro, 3810-193 Aveiro, \\ Portugal; E-Mail: jpbento@ua.pt \\ * Corresponding author
}

Submitted: 29 December 2017 | Accepted: 6 February 2018 | Published: 17 May 2018

\begin{abstract}
This case-study conducted in Norway investigates employers' responses to policy measures implemented throughout 2006-2015 and aimed at promoting the inclusion of persons with disabilities (PwDs) into mainstream employment by providing workplace adaptations. For this purpose, we apply a multi-method approach by combining in-depth qualitative interviews conducted with the managers at two large private companies in Norway and quantitative shift-share analysis performed on the Norwegian Disabled People LFS data. While the shift-share analysis has demonstrated positive effects in the employment of PwDs at the national level and in providing adaptations at work during 2011-2015 for 'changes of working time', 'need for one or more adaptations' and 'changes of work tasks', 'physical adaptations' remain negative. The qualitative interviews report that 'flexibility' or 'changes of working time' is the main workplace adaptation the managers at both companies provide to own employees who return to work after acquiring a disability or having a long-term illness Both companies demonstrate high conformity to accessibility standards, however, the provision of workplace adaptations to PwDs without prior work experience remains limited or absent despite the disability policy measures in Norway in that period and the companies' commitment to inclusion.
\end{abstract}

\section{Keywords}

accessibility; anti-discrimination; company; disability; employment; legislation; workplace adaptations

Issue

This article is part of the issue "Global Perspectives on Disability", edited by Shaun Grech (The Critical Institute, Malta) and Karen Soldatic (Western Sydney University, Australia).

(C) 2018 by the authors; licensee Cogitatio (Lisbon, Portugal). This article is licensed under a Creative Commons Attribution 4.0 International License (CC BY).

\section{Introduction}

Persons with disabilities (PwDs) have long been excluded from mainstream employment due to multiple discriminatory barriers (Hogan, Kyaw-Myint, Harris, \& Denronden, 2012; Vornholt, Uitdewilligen, \& Nijhuis, 2013). The 'social model' of disability since its adoption in the 1970s has framed a new disability policy paradigm aimed at removing disabling societal barriers by promoting non-discrimination, equal treatment, and accessible environments (Lawson \& Priestley, 2017). The EU Employment Equality Framework Direc- tive (Council Directive 2000/78/EC, 2000) and the UN Convention on the Rights of Persons with Disabilities (UN CRPD) impose on employers the duty to provide 'reasonable accommodation' or 'appropriate modification, adaptations and/or adjustments' to enable PwDs 'to have access to, participate in, or advance in employment...and in work environment that is open, inclusive and accessible'. This duty is required to be transposed into national law and is considered a 'substantive equality measure having the potential to result in fundamental structural transformations' (Kayess \& French, 2008, p. 9). 
First adopted in the US and the UK, the antidiscrimination legislation has gradually evolved in the majority of European countries (Waddington, 2013). Nevertheless, alongside the anti-discrimination legislation, many EU countries continue to operate the quota system that puts employers of a certain size and in both the private and public sectors, under a strict obligation to employ a fixed percentage of PwDs. Compliance, however, remains relatively low (Fuchs, 2014; Moody et al., 2016; OECD, 2003). Instead, the 'reasonable accommodation duty' introduced by anti-discrimination legislation does not specify or limit the range of accommodations (Balser, 2007) and is believed to ensure PwDs equal access to mainstream employment (Hvinden, 2013; Schur et al., 2014). Furthermore, employers are expected to take action only if 'accommodation' does not lead to excessive costs or turns into 'a disproportionate burden' (Waddington, 2008).

Nevertheless, employers often express concerns about adaptation costs preventing them from hiring and/or retaining PwDs (Erickson, Schrader, Bruyère, VanLooy, \& Matteson, 2014; Henry, Petkauskos, Stanislawzyk, \& Vogt, 2014; Hernandez et al., 2009; Vornholt et al., 2013). Indeed, provision of workplace adaptations depends on PwDs' needs, and may vary from alterations/adaptations of buildings and facilities to purchase of necessary assistive technology/equipment and/or require modifications of work tasks/schedules (Balser, 2007; Hernandez et al., 2009; Nevala, Pehkonen, Koskela, Ruusuvuori, \& Anttila, 2015). In practice, workplace adaptations may involve limited costs and are beneficial both to employers and PwDs (Hartnett, Stuart, Thurman, Loy, \& Batiste, 2011; Nevala et al., 2015; Schartz, Hendricks, \& Blanck, 2006; Schur et al., 2014). In particular, providing workplace flexibility by modifying job tasks, work scheduling and/or location appears not to be costly, though it does require on-going effort (Padkapayeva et al., 2016). Public financial support is available to cover a part of adaptation costs for employers (Hvinden, 2013). Still, employers may demonstrate prejudices and stereotypes against persons with certain types of disabilities, in particular, psychiatric disabilities, learning disabilities and/or mental illnesses, who would require greater supervision and attention (Ju, Roberts, \& Zhang, 2013; McDowell \& Fossey, 2015; Zissi, Rontos, Papageorgiou, Pierrakou, \& Chtouris, 2007).

Prior research has argued that concerns about costs are mainly expressed by small and medium-sized companies, whereas large companies have sufficient financial and human resources and policies in place, as well as an inclusive organisational culture, that allow them to provide the necessary workplace adaptations (Erickson et al., 2014; Hernandez et al., 2009; Ju et al., 2013; Morgan \& Melina, 2005; Schartz et al., 2006). Other researchers, on the contrary, have argued that large companies' public commitments to non-discrimination, equality and accessibility standards, positive attitudes and explicit global inclusive strategies may not always translate into positive hiring decisions for PwDs (Ball, Monaco, Schmeling, Helen, \& Blanck, 2005; Ju et al., 2013). Still, despite their size, large companies may also express concerns about costs and state their need for additional support to include PwDs (Henry et al., 2014; Hernandez et al., 2009; Kaye, Jans, \& Jones, 2011). Despite best practices of disability inclusion (e.g., ILO, 2010), and limited case-studies on accessibility (e.g., Sandler \& Blanck, 2005), how large companies respond to disability policy measures and ensure the inclusion and adaptations for PwDs, remains under researched.

Unlike the rest of Europe, the Nordic countries have traditionally been portrayed as generous welfare states, where high employment rates, equality standards, and employers' corporate social responsibility and contribution to social inclusion are well-established (Halvorsen, Hvinden, \& Schøyen, 2015; Mandal \& Ose, 2015; OECD, 2017). In Nordic countries, a 'relational model of disability' that views disability as 'relative to the environment' has been prevalent in public policy since the 1970s (Tøssebro, 2004, p. 4). This understanding has been less radical in removing existing societal barriers than a 'social model' of disability (Halvorsen \& Hvinden, 2009; Tøssebro, 2016). Nordic countries have not implemented quotas in mainstream employment, but have prioritised rehabilitation, vocational training, job placement services (e.g. work training in regular workplaces) and, in some cases, publicly subsidised and sheltered jobs at private companies, and provided considerable public support to employers and to PwDs (Duell, Singh, \& Tergeist, 2009; Halvorsen \& Hvinden, 2009). However, despite visible similarities, practical responses and newly adopted social regulatory policy measures to achieve the highest employment rates and make employers responsible differ at the national levels (Halvorsen et al., 2015). Therefore, Tøssebro (2016) appoints to the need for more research on the effects that current disability social regulation policies in Nordic countries, particularly in Norway, have on the workplace adaptations provided to PwDs.

Given this background, the present case-study has been conducted in Norway to explore how policy measures implemented over the period 2006-2015 have impacted employers' responses to ensuring the inclusion of PwDs in mainstream employment by providing adaptations at work.

\section{Policy Measures Promoting Employers' Responsibility to PwDs in Norway}

In Norway, the employers' obligation to ensure proper working conditions for employees has been primarily regulated by The Work Environment Act (Arbeidsmiljøloven) since 1977 (WEA, last amended in 2015). However, the WEA did not provide any protection for PwDs against discrimination until 2004, when, following the EU Directive (2000/78/EC), it incorporated stricter measures to oblige employers to adapt the workplace for PwDs. These were 
mainly aimed at their own employees (Hvinden, 2004; Vedeler, 2014). The most recent WEA amendments of 2015 concerned temporary employment and working hours that were argued to ensure more flexibility and increase the chances for PwDs to enter working life (Dahl \& Lorentzen, 2017).

Furthermore, based on its corporative tradition, Norway has given high priority to promoting employers' voluntary commitment. A More Inclusive Working Life Agreement (hereafter, 'IA Agreement'), in effect since 2001, aims to increase employers' responsibility (both in the public and private sectors) for own employees and for the unemployed vulnerable groups (Dahl \& Lorentzen, 2017; Mandal \& Ose, 2015). This is a voluntary tripartite agreement signed between the three social partners: the government (Norwegian Welfare Directorate-NAV), the employers' organisations and the social partners (trade/labour unions). The IA Agreement commits employers to implementing three goals: 1) reducing sickness absence and facilitate working conditions for [own] employees with special needs, 2) promoting employment of people with reduced functional abilities recommended by NAV, and 3 ) retaining ageing workers. The regional NAV Working Life Centres provide various types of support including financial assistance that covers workplace adaptation costs, advisory support, follow up, etc. (Mandal \& Ose, 2015). The IA Agreement has been renewed several times, the latest for the period of 2014-2018, with the majority of medium and large private companies having signed it (Olsen, Svendal, \& Amundsen, 2005; Ose, Brattlid, \& Slettebak, 2013). While the number of PwDs reported by the IA enterprises has increased, slightly more in the public sector than in the private, challenges have been reported with regard to facilitating the workplace for PwDs with chronic illnesses, musculoskeletal disorders and mental disorders (Hansen \& Haualand, 2012; Svalund \& Hansen, 2013). Additionally, the Jobs Strategy for PwDs (2011-13) accompanies the IA Agreement and aims to promote work-experience programmes specifically for young PwDs, mainly in the public sector.

Influenced by the international and European antidiscrimination and equality laws, Norway also adopted The Anti-Discrimination and Accessibility Act (ADAA) in 2009 (amended in 2013) (Halvorsen \& Hvinden, 2009; Tøssebro, 2016). The aim of the ADAA is to intensify the duty on public employers and private-sector employers with more than 50 employees to ensure nondiscrimination and to provide reasonable accommodation for PwDs outside the workplace, and to introduce 'the universal design' standards. Small enterprises remain exempt from this obligation (Svalund \& Hansen, 2013). The ADAA prepared the ground for Norway's ratification of the UNCRPD in 2013 (Strand, 2014). However, simple and inexpensive workplace adaptations prevail (Tøssebro, 2016), and some scholars argue that enforcement of the 'accommodation' duty in Norway remains relatively weak (Halvorsen \& Hvinden, 2014).

\section{Methods}

The case-study method allows to study 'events within their real-life context' (Yin, 2009). However, to understand the full complexities of national policies on workplace adaptations, Vedeler and Schreuer (2011) recommend applying a multi-method approach. This casestudy adopts an inductive qualitative approach (Morse, 2003, p. 199) and uses two different data sources gathered separately: in-depth qualitative interviews and a quantitative analysis performed on national statistical data. The qualitative component allowed us to collect in-depth information on companies' practices regarding the inclusion of PwDs. A quantitative component was sequentially added to support the core qualitative approach, and to compare the results obtained from the analysis of the companies.

For collecting qualitative data, the objective was to select 'successful or positive cases' where the outcome of interest occurs (Mahoney \& Goertz, 2006). The main selection criteria, therefore, concerned large private companies (with $250+$ employees) that operate in Norway and have a commitment to include PwDs among their workforce. To simplify access to potential companies, the first author asked for an 'endorsement from a higher authority' (Flick, 2006, p. 116)recommendations from the employers' association and a trade union in Norway. In total, out of the 11 large companies recommended, eight corresponding to the selection criteria were selected for further contact. Only two, however, agreed to participate: one multinational consulting company represented in Norway and headquartered in the US (C1), and one Norwegian multinational engineering company represented in approximately 20 countries worldwide (C2). The other companies declined for different reasons, such as already taking part in similar research, insufficient time to participate in an in-depth study or having no PwDs among their employees.

The open-ended and semi-structured interviews (with an average duration of 60 minutes) were conducted in English by the first author between August and November 2012 with the senior and middle-level managers at the premises of the two companies. The HR managers became the 'key contacts' who provided information and access to other interviewees. Each interviewee signed the individual consent form which stipulated that the names of the companies and personal data of the interviewees would not be disclosed. For this study, 12 interviews are presented:

- Country manager, HR leader, HR/diversity manager, HR senior analyst, supervisor, Consultant/ Project leader at $\mathrm{C} 1$; and

- Diversity manager, HR/inclusion manager, HR manager, HR administrative manager, HSE manager, Department manager/Supervisor at C2. 
The interviews were analysed using the inductive thematic analysis with the help of the qualitative software Nvivo (Bazeley \& Jackson, 2013). The main goal was to study the 'phenomenon' through the personal experiences of 'insiders' and not to collect data based on a predefined hypothesis (Yin, 2009).

The data for the quantitative analysis were collected and analysed by the second author in 2016 from the Norwegian Disabled People Labour Force Survey (LFS) for the period 2006-2015. These data cover PwDs aged 15-66, their labour force status, and work adaptations before and after job start (SSB, 2016). LFS defines 'disability' in terms of 'a difficulty to perform any daily activity, due to a longstanding health problem', and is based on whether survey respondents perceive themselves as having a disability (or a 'functional impairment' in Norwegian translation). To perform the shift-share analysis, the data set was divided into 5-year intervals taking into account policy measures that promote the inclusion of PwDs in each period: 1) 2006-2010 covering the IA Agreement and the WEA provisions; and 2) 2011-2015 including the ADAA together with other ongoing policy measures. The results were verified and discussed between the authors, and then compared to the results of the qualitative interviews.

\section{Results}

\subsection{Results of the Interview Analysis}

The results of the qualitative interviews demonstrate the experiences of the responsible managers at two large companies in Norway with ensuring the inclusion of PwDs in mainstream employment, providing adaptations at work, as well as their awareness of the evolving disability policy measures. The thematic analysis of the interviews revealed 'workplace adaptations' to be one of the main overarching theme consisting of four sub-themes: 'providing adaptations in response to policy measures'; 'changes of work tasks'; 'changes of working time'; and 'physical adaptations'.

\subsubsection{Providing Adaptations in Response to Policy Measures}

The interviewees at both companies demonstrated general awareness about non-discrimination, equality and accessibility standards. However, they associated it with neither the UN CRPD nor with the antidiscrimination law. Neither company had a corporate policy to specifically address non-discrimination, equal treatment and/or accommodation of PwDs since their global corporate policies already included these principles. The Country manager at C1 mentioned "The Global Corporate Guide on inclusive and accessible workplace", but the HR managers in the Norwegian office did not consider it applicable in their local practices. The interviewees from C2 mentioned corporate HSE policy as the main policy regulating workplace adaptations for employees.

The interviewees at both companies expressed high awareness of accessibility norms in relation to buildings/facilities, though they did not relate these explicitly to anti-discrimination legislation:

Every building [constructed] after 2010 should have an entrance adapted for wheelchair users. (HR senior analyst, C1)

There are requirements from the government for new buildings. (HR/diversity manager, $\mathrm{C} 1$ )

We meet all necessary building accessibility [requirements] and have no problem in having PwDs. (HR manager, C2)

Instead, the interviewees at C1 expressed concerns about the accessibility of their clients' premises, especially if employees with disabilities were supposed to work on projects:

There will be no problem in our building if you are on a wheelchair, though it might be heavy to work at a client's site. (Consultant/Project leader)

In that [client's] place it may not be possible to come in a wheelchair. (HR leader)

At the local office of $\mathrm{C} 2$, the interviewees reported problems connected with local transportation. However, the corporate office provided a "free bus to take employees to work and back home" (Diversity manager).

The interviewees at both companies, however, had not experienced recruiting PwDs who would require substantial workplace adaptations. The HR managers at both companies reported that they "never had job applicants in wheelchairs" and did not specifically set out to recruit PwDs. Consequently, they mentioned that no adaptations were provided during recruitment, however, assured to provide it, whenever required, in accordance with non-discrimination and equality standards. The interviewees at C2 considered it would be impossible to hire PwDs for offshore posts, contrary to office-related positions, because of their strict health requirements.

Furthermore, both companies joined the IA Agreement in 2001 (with the exception of the C2's corporate office). The interviewees, however, did not report providing PwDs with work training opportunities at their companies. Instead, they favoured mainly older employees and those returning after long-term sicknesses/illnesses, who did not require workplace adaptations. Mandal and Ose (2015), Vedeler and Schreuer (2011) and Ose, Brattlid and Slettebak (2013) argued that the public sector in Norway made higher commitments to adapting working conditions and recruiting PwDs than the private sector, therefore PwDs mainly applied for positions in the pub- 
lic sector. The interviewees themselves mentioned that other companies (also in the public sector) "are doing better than them" in including PwDs.

\subsubsection{Changes of Work Tasks}

According to Nevala et al. (2015) and Vedeler and Schreuer (2011), modifying duties for employees who cannot perform former job functions because of disability is important. The interviewees at both companies, however, did not report making significant changes in work tasks for PwDs. At C1, the supervisor told of one employee who they retained after acquiring a disability (not work-related) and who performed the same work tasks because he "was a really good specialist". At C2, the HR managers reported that they could facilitate "different kinds of things for PwDs-even substitute some work tasks", however, all work adaptations needed to be discussed with managers/supervisors responsible. The interviewees also mentioned that PwDs might have "hidden or invisible" impairments they could not disclose, as well as their needs for adaptations, when applying for jobs. Prior research confirmed that PwDs did not disclose their disabilities and concealed invisible impairments because of existing prejudices and fear of discrimination (Foster \& Wass, 2012).

The managers at both companies reported higher chances of changing work tasks for their own employees after sicknesses or long-term illnesses/disabilities, as required by the WEA and corporate HSE policy. For instance, at C2, offshore employees who got injured and could not continue working offshore were relocated, requalified and given other office-related duties. However, the interviewees considered to adapt the work tasks for "new PwDs", especially those with intellectual impairments, very challenging:

We select candidates for work training based on their prior experience to perform certain work tasks. (HR/diversity manager; HR leader, C1)

It is difficult to arrange work tasks for persons with mental illnesses, that goes beyond just providing a new chair or hoping a person gets better. (HR/inclusion manager, C2)

It is easier if a person is disabled in some physical way, like having an arm that does not work, because we work in teams and it would be a problem if somebody cannot interact with others. (HR administrative manager, C2)

Our company is not a kindergarten [that has] to arrange the work tasks specifically for these people. (Department manager/Supervisor, C2)

These findings show the importance of the managers and supervisors' attitudes towards PwDs and how this affects their handling of accommodation requests, which is in line with the findings of Hogan et al. (2012), and and Schur et al. (2014). Still, at both companies, the main responsibility for the inclusion of PwDs was principally on the HR managers, with the supervisors showing reluctance to engage.

\subsubsection{Changes of Working Time}

Prior research has found that changes in work schedules is the most common workplace adaptation measure provided by employers (Padkapayeva et al., 2016; Schur et al., 2014). Likewise, the interviewees in this study confirmed that the most frequently provided workplace adaptation was changes of working time-flexible or reduced working hours, working from home and parttime positions. "I was given flexibility to work from anywhere....If I had to work full-time, I would never make it", reported $\mathrm{HR} /$ diversity manager at $\mathrm{C} 1$ who experienced coming back to work after long-term sick leave. The supervisor at C1 who likewise came back after a long-term sick leave also initially worked only a $50 \%$ schedule. He also mentioned that an employee with acquired disability after retention "worked on reduced time schedule, did not work overtime, and did not perform demanding work". The Consultant/Project lead remembered working on a project with a person with a hearing difficulty, who "was given flexibility and could have longer breaks and/or did not work in the afternoons". The HR interviewees from C2 mentioned that they "were extremely flexible, especially, if somebody got injured". The HR managers mentioned that employees on sick leave could have remote access to work from home. The Department manager added that employees were generally allowed to stay at home if they had children or for some other valid reason, because he considered important "taking care of own employees and providing them with flexibility".

All these measures, however, were targeting own employees, who got sick or returned to work after sick leave. Nothing was mentioned regarding newly hired PwDs and especially those with congenital disabilities. The interviewees at C1 mentioned that it might be more difficult to "sell consultants on a reduced work schedule less than $80 \%$ " or "substitute a person for a long time". These findings confirm prior research (Halvorsen \& Hvinden, 2009, 2014) that considered employers in Norway more likely to arrange the necessary provision for their own employees than for PwDs without any employment experience. Despite McDowell and Fossey (2015) showing that flexible scheduling/reduced hours could also be an important type of workplace adjustment for employees with mental illnesses, the interviewees did not report any accommodations provided for them, instead showing prejudices against their being hired or accepted for work training. 


\subsubsection{Physical Adaptations of Workplace}

Padkapayeva et al. (2016) argued that modifying workstations to meet the needs of PwDs is also an important workplace adaptation measure besides arranging accessibility of the building/facilities. Regarding accessibility of buildings/facilities, the interviewees considered their companies having all necessary conditions for disabled employees:

If we had an applicant in a wheelchair, it would not be a problem as this building is accessible. (HR leader, C1)

We have all necessary accessible facilities, especially for employees in wheelchairs and/or with audiovisual disabilities. (HR manager, $\mathrm{C} 2$ )

Easily accessible premises. (Diversity manager, C2)

Adapted elevators and toilets. (HSE manager, C2)

Renovated building and accessible parking spaces. (HR/inclusion manager, C2)

However, the interviewees at both companies regarded the corporate building/office as more suitable for PwDs due to its more accessible working conditions and the prevalence of office-related positions.

Regarding workplace modifications, the interviewees at both companies mentioned changing computer desks, providing special chairs or changing the workplace location for own employees. At C1, the HR interviewees provided "special phones for an employee with a hearing disability" and "reading glasses for an employee who had acquired disability". The Consultant/Project leader also reported accommodating an employee with a hearing difficulty by changing her table position. The supervisor mentioned providing "a predictable working environment with less noise" for an employee with acquired disability "to work without disturbances". However, these adaptations neither involved high costs to the companies nor financial support from NAV. Only one employee with acquired disability received a subsidy from NAV that partially covered his travel costs to and from work, which he had requested himself.

The interviewees at C2 did not experience providing as many workplace adaptations as at $\mathrm{C} 1$. Both corporate and local offices of $\mathrm{C} 2$ had occupational physiotherapists, who regularly evaluated employees' adaptation needs, and HSE managers, who supervised employees' working conditions, as required by the HSE and WEA regulations. However, the interviewees at C2 stressed that it would still be easier for them to accommodate "a person who is disabled in some physical way than a person with social or intellectual problems". The interviewees from C2 did not request any financial support from NAV for providing physical adaptations at the workplace since they considered it "a time-consuming and bureaucratic process". These findings are in accordance with Vedeler and Schreuer (2011) who confirmed that the process of getting public support and funding was complicated, and argued that providing workplace adaptations instead greatly depended on managers' willingness and initiatives.

\subsection{Results of Shift-Share Analysis}

The quantitative analysis has targeted to explore the national employment growth of PwDs and adaptations provided in Norway between 2006-2010 and 2011-2015. For this purpose, an enhanced version of the shift-share method (Artige \& van Neuss, 2014; Gialis \& Tsampra, 2015) was applied that allowed to decompose data into 'subsets' and 'subgroups' to assess changes in employment of PwDs and workplace adaptation measures. The 'subsets' cover PwDs 'whose jobs have not been adapted' and those 'whose jobs have been adapted'. The 'subgroups' contain the types of adaptations defined by Statistics Norway (see Table 1). This method computes a combination of three shift-share effects. The first comprises the 'national growth effect' (NE) that explains how much of the adaptations subgroup's growth in employment of PwDs may be attributed to the overall growth of employment of PwDs at the national level. The second is the 'subset growth effect' (SE) that represents the adaptations subgroup's growth in employment of PwDs that is due to the employment growth in one of the two subsets at the national level. The third is the 'subgroup growth effect' in a subset, which is also known as the 'competitive effect' (CE). This indicates how much change in a subset may be explained by particular advantages that the subgroup possesses. A positive CE for an adaptation subgroup in a subset indicates that the subgroup is outperforming national trends. A negative CE effect indicates that a subgroup in a subset is underperforming compared to national trends. This method requires that the sum of all the shift-share components for any given subgroup must equal the total growth rate of PwDs employment for the same subgroup in each period.

Positive changes are reported by NE in both periods. The total growth rate of PwDs was higher in 2011-2015 than in $2006-2010,18.8 \%$ and $4.3 \%$ respectively (see Table 1). The growth rate of SE in the subgroup 'need for one or more adaptations' switched from a negative value to a positive one between the two periods, arguably demonstrating the increase of employed PWD and of provided adaptations. Positive growth rates of CE were observed in the second period for 'need for one or more adaptations', 'changes of work tasks' and 'changes of working time'. The CE effect for subgroup 'physical adaptations of workplace' remains with a negative growth rate, although it was smaller in magnitude compared to the first period. The remaining two subgroups, 'no need for adaptation' and 'changes of work tasks', show decreasing growth rates of CE from the first period to the second. The subgroup 'changes of working time' shows 
Table 1. Results of shift-share analysis

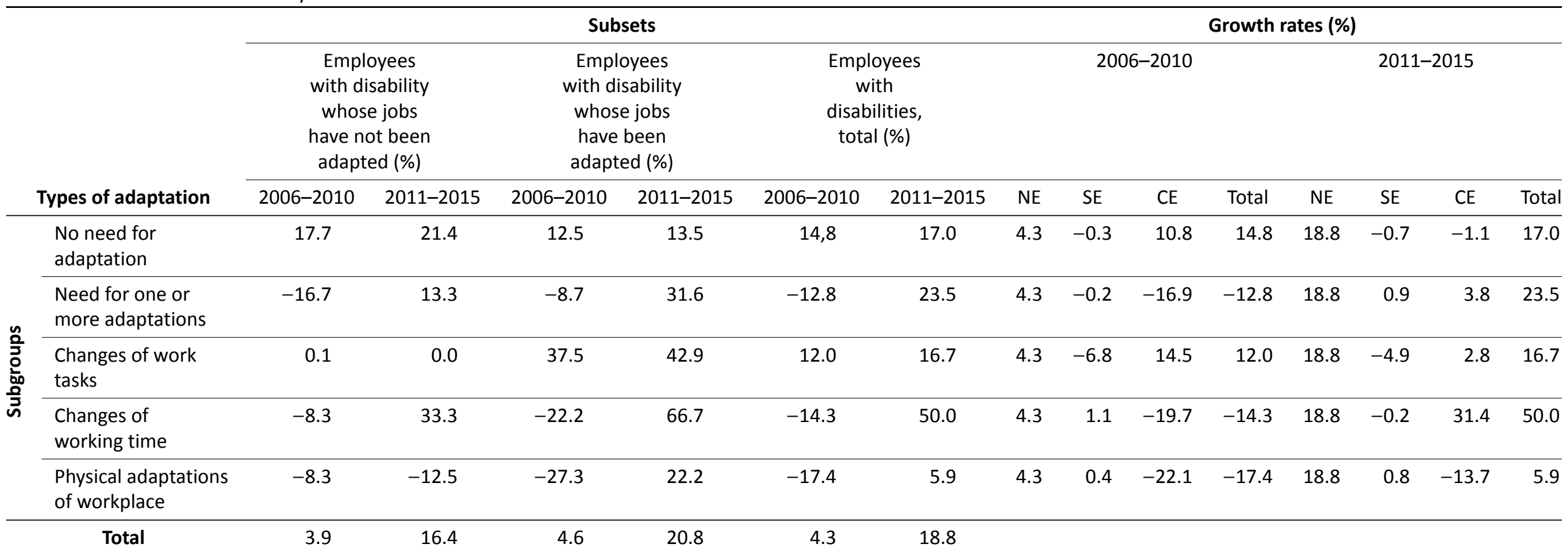

Note: Calculations performed on Statistics Norway data (SSB, 2016). 
the highest positive growth rate of CE between 20062010 and 2011-2015, while 'physical adaptations of workplace' presents the highest negative value. The abovementioned growth effects are presented graphically in Figure 1 . In conclusion, the shift-share analysis reveals that CE demonstrates stronger effects than the other effects (NE and SE). This is particularly visible in the second period showing that 'changes of working time', 'need for one or more adaptations' and 'changes of work tasks' have been given more importance by the Norwegian employers. The CE of 'no need for adaptation' decreased from the first to the second period, compared to 'need for one of more adaptations', suggesting employers' greater responsiveness towards PwDs who need adaptations.

\section{Concluding Discussion}

This case-study has applied a multi-method approach based on qualitative interviews at two large companies and quantitative shift-share analysis on the LFS data on Norway to explore employers' responses to policy measures in ensuring the inclusion of PwDs in mainstream employment by providing adaptations at work.

The shift-share results demonstrated considerable growth in employment of PwDs and in provision of adaptations at work at the national level from the first period (2006-2010) to the second (2011-2015). From these findings, we may infer that during the last period, when all policy measures - the anti-discrimination legislation, the IA Agreement and the labour law (WEA), are in place, employers have become more responsive to including PwDs in mainstream employment and providing workplace adaptations. In contrast, from the interviewees' responses at two large companies, there was no indication that workplace adaptations were made for PwDs without prior work experience, because there were no such job applicants or trainees. Despite the high accessibility standards of the companies' buildings and facili-

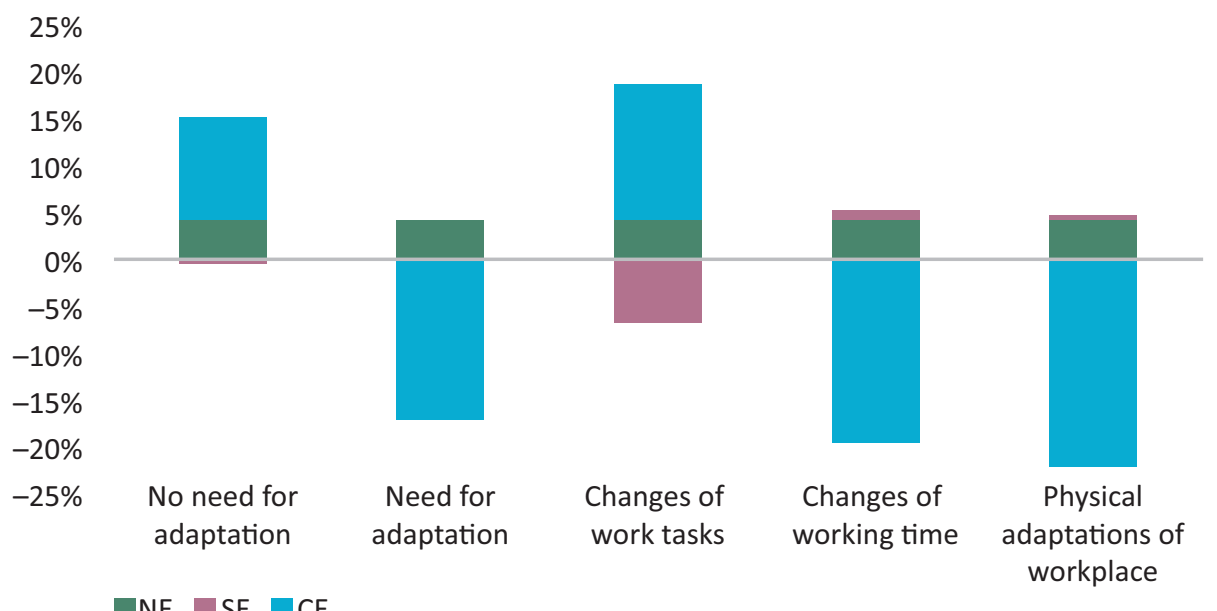

2011-2015

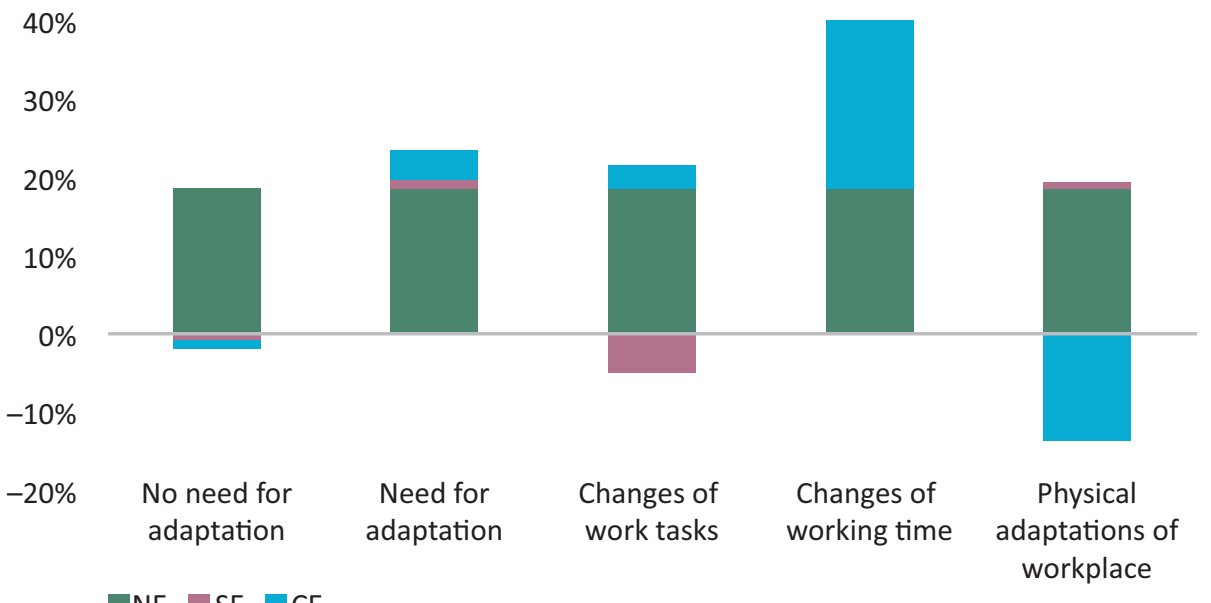

Figure 1. Graph of shift-share analysis. 
ties, the corporate policies only broadly addressed nondiscrimination and equality obligations; they did not refer specifically to anti-discrimination legislation, and accessibility standards were not applied during the recruitment process. Likewise, Halvorsen and Hvinden (2014), argued that Norwegian employers were often willing to accommodate the needs of employees yet claimed that they did not receive applications from persons who explicitly state that they are disabled.

Regarding specific types of provided adaptations, the shift-share analysis highlighted important changes for 'changes of working time', 'need for one or more adaptations' and 'changes of work tasks'. The qualitative interviews, likewise, demonstrated that workplace adaptations such as changes of work tasks and working time were those most often provided, though mainly to own employees who acquired disabilities or returned to work after long-term illnesses. These responses also referred to the companies' conformity to the national labour legislation-WEA, to the IA Agreement, and to the corporate HSE policy-all requiring employers to improve working conditions for own employees. This finding, however, is not new, as prior research has indicated the prevalence of retaining current employees and reducing their sick leave rather than increasing the employment prospects of PwDs outside the labour market (Dahl \& Lorentzen, 2017; Halvorsen \& Hvinden, 2014).

The result of the shift-share analysis for 'changes of working time' in 2011-2015 may indicate the increased importance of 'flexibility'. This may be associated with temporary employment, where many PwDs are employed, according to Ekberg et al. (2016). This finding may likewise reflect the prevalence of part-time work among PwDs in Norway, which might have also increased due to recent changes in WEA, as reported by Dahl and Lorentzen (2017). However, the interviewees did not report any PwDs employed part-time or on a reduced work schedule and, in fact, rejected the possibility of their being employed for part-time positions. The flexible arrangements provided, mainly concerned own employees, though this did not bring more PwDs into mainstream employment, especially those with mental (or more severe) impairments, who would require flexible scheduling and support (McDowell \& Fossey, 2015). With regard to 'physical adaptations', the shift-share result shows this to be lagging behind. Both companies reported ensuring accessible buildings and/or facilities but did not provide more substantial workplace adaptations because there were no PwDs who would require these adaptations. As argued by Erickson et al. (2014), job applicants may be unaware that they can request accommodations. However, the prevalence of workplace adaptations provided mainly for persons with physical disabilities arguably indicates a lack of prior experience in providing adaptations for employees with other types of impairments and reveals the prejudices the managers might have against PwDs with more severe disabilities.
While we could not draw any conclusions from the shift-share analysis regarding costs involved in workplace adaptations, the qualitative interviews revealed that the responsible managers did not request financial support from NAV. This was because many of provided adaptations were not costly and the interviewees did not report having PwDs among their trainees (or employees) who would require substantial workplace adaptations that might result in excessive costs. This finding is in line with Ose et al. (2013) and Dahl and Lorentzen (2017) who argued that even though employers were eligible for financial support for reasonable accommodation, recruiting PwDs had been given lower priority than reducing sick-leave absence and early retirement from working life of own employees in Norway. Halvorsen and Hvinden (2014) confirmed that the burdens for co-workers appeared to be of larger concern than the costs to accommodate PwDs in the workplace. In line with prior research (Ose et al., 2013; Svalund \& Hansen, 2013), the major funding was therefore provided to public companies in Norway that demonstrated greater awareness and involvement in including PwDs.

In conclusion, it can be stated that despite the antidiscrimination legislation obligations and the 'reasonable accommodation duty' aimed at promoting the inclusion of PwDs in mainstream employment, provided adaptations may, in practice, depend more on the HR managers' or supervisors' attitudes and decisions, and on the companies' policies than on associated costs. While the managers do not disregard the importance of the nondiscrimination, equal treatment and accessibility standards mentioned in the corporate policies, this has so far not resulted in their active inclusion of PwDs among the workforce. And, whereas the responsible managers may associate providing workplace adaptations mainly with employees with mobility or sensory disabilities, the provision of more substantial adaptations to persons with other types of impairments is still limited, as also demonstrated by the two companies in this case-study. The results obtained, therefore, reveal a discrepancy between the employment changes in the shift-share data of PwDs and the responses from the interviews that show the companies' practices in this respect.

This case-study has significant limitations. From these findings, it is not possible to make generalised conclusions regarding type of industry and/or disability, and the practices of other large companies in Norway or any other countries. The interviews were conducted predominantly with managers responsible for policy implementation, which could potentially result in them controlling the obtained data and reflect their own perspectives. Moreover, given the data limitations, the shift-share analysis, applied here to provide additional insights into the research question, does not claim any causal relationship between the adaptations provided and employment of PwDs. With this in mind, future research may consider examining in more detail such causal relationships by conducting a large-scale survey that involves a 
random sample of a larger number of companies in different business sectors (both public and private). Additionally, the first-hand experience of PwDs, who are either already employed at the companies and have received adaptations at work or are job applicants who need adaptations, could be considered. Furthermore, issues that may require greater attention in future research would be flexible working arrangements and part-time employment, which emerged as important workplace adaptations from this study.

\section{Acknowledgements}

The authors would like to thank all the interviewees for their contributions to this study, as well as the anonymous reviewers for their valuable comments.

\section{Conflict of Interests}

The authors declare no conflict of interests.

\section{References}

Artige, L., \& van Neuss, L. (2014). A new shift-share method. Growth and Change, 45(4), 667-683. doi:10.1111/grow.12065

Ball, P., Monaco, G., Schmeling, J., Helen, S., \& Blanck, P. (2005). Disability as diversity in Fortune $100 \mathrm{com}-$ panies. Behavioral Sciences and the Law, 23(23), 97-121. doi:10.1002/bsl.629

Balser, D. B. (2007). Predictors of workplace accommodation for employees with mobility-related disabilities. Administration and Society, 39(5), 656-683.

Bazeley, P., \& Jackson, K. (2013). Qualitative data analysis with Nvivo (2nd ed.). London: SAGE.

Dahl, E., \& Lorentzen, T. (2017). Employment policy and social investment in Norway. In J. Midgley, E. Dahl \& A. Conley (Eds.), Social investment and social welfare: International and critical perspectives (pp. 87-104). Morthampton, MA: Edward Elgar Publishing.

Duell, N., Singh, S., \& Tergeist, P. (2009). Activation policies in Norway (OECD Social, Employment and Migration Working Papers, 78). Paris: Organisation for Economic Co-operation and Development (OECD).

Ekberg, K., Pransky, G. S., Besen, E., Fassier, J.-B., Feuerstein, M., Munir, F., \& Blanck, P. (2016). New Business structures creating organizational opportunities and challenges for work disability prevention. Journal of Occupational Rehabilitation, 26(4), 480-489. doi:10.1007/s10926-016-9671-0

Erickson, W. A., Schrader, S. v., Bruyère, S. M., VanLooy, S. A., \& Matteson, D. S. (2014). DisabilityInclusive employer practices and hiring of individuals with disabilities. Rehabilitation Research, Policy, \& Education, 28(4), 309-328(320). doi:10.1891/21686653.28.4.309

Flick, U. (2006). An introduction to qualitative research (3rd ed.). Thousand Oaks, CA: SAGE.
Foster, D., \& Wass, V. (2012). Disability in the labour market: an exploration of concepts of the ideal worker and organisational fit that disadvantage employees with impairments. Sociology, 47(4), 705-721 doi:10.1177/0038038512454245

Fuchs, M. (2014). Quota systems for disabled persons: Parameters, aspects, effectivity (Policy Brief, March 2014). Retrieved from http://pdc.ceu.hu/archive/ 00007076/01/ECSWPR_Quota-systems-for-disabledpersons_2014.pdf

Gialis, S., \& Tsampra, M. (2015). The diverse regional patterns of atypical employment in Greece: Production restructuring, re/deregulation and flexicurity under crisis. Geoforum, 62(175), 175-187.

Halvorsen, R., \& Hvinden, B. (2009). Nordic disability protection meeting supranational equal treatment policy: A boost for the human rights of persons with disabilities? In H. S. Aasen, R. Halvorsen, \& A. B. d. Silva (Eds.), Human rights, dignity and autonomy in health care and social services: Nordic perspective (pp. 177-203). Cambridge: Intersentia.

Halvorsen, R., \& Hvinden, B. (2014). Nordic reforms to improve labour market participation of vulnerable youth: An effective new approach? International Social Security Review, 67(2), 29-47.

Halvorsen, R., Hvinden, B., \& Schøyen, M. A. (2015). The Nordic welfare model in the twenty-first century: The bumble-bee still flies! Social Policy and Society, 15(1), 57-73. doi:10.1017/S1474746415000135

Hansen, I. L. S., \& Haualand, H. (2012). Diskriminerende barrierer i arbeidslivet. Aktivitets- og rapporteringsplikt som virkemiddel for området nedsatt funksjonsevne [Discriminatory barriers in working life. Activities and reporting obligation regarding persons with disabilities]. Oslo: Fafo.

Hartnett, H. P., Stuart, H., Thurman, H., Loy, B., \& Batiste, L. C. (2011). Employers' perceptions of the benefits of workplace accommodations: Reasons to hire, retain and promote people with disabilities. Journal of Vocational Rehabilitation, 34(1), 17-23. doi:10.3233/ JVR-2010-0530

Henry, A., Petkauskos, K., Stanislawzyk, J., \& Vogt, J. (2014). Employer-recommended strategies to increase opportunities for people with disabilities. Journal of Vocational Rehabilitation, 41, 237-248. doi:10.3233/JVR-140716

Hernandez, B., McDonald, K., Lepera, N., Shahna, M., Wang, A. T., \& Levy, J. M. (2009). Moving beyond misperceptions: The provision of workplace accommodations. Journal of Social Work in Disability \& Rehabilitation, 8(3/4), 189-204. doi:10.1080/ 15367100903202755

Hogan, A., Kyaw-Myint, S. M., Harris, D., \& Denronden, H. (2012). Workforce participation barriers for people with disability. International Journal of Disability Management, 7, 1-9. doi:10.1017/idm.2012.1

Hvinden, B. (2004). Nordic disability policies in a changing europe: Is there still a distinct nordic model? So- 
cial Policy and Administration, 38(2), 170-189.

Hvinden, B. (2013). Disability. In B. Greve (Ed.), The Routledge handbook of the welfare state (pp. 371-380). Oxford: Routledge.

ILO. (2010). Disability in the workplace: Company practices. Geneva: International Labour Organization Retrieved from http://www.businessanddisability. org/index.php?option=com_content\&view=article\& id=92\&ltemid=68\&lang=en

Ju, S., Roberts, E., \& Zhang, D. (2013). Employer attitudes toward workers with disabilities: A review of research in the past decade. Journal of Vocational Rehabilitation, 38, 113-123. doi:10.3233/JVR-130625

Kaye, H. S., Jans, L. H., \& Jones, E. C. (2011). Why don't employers hire and retain workers with disabilities? Journal of Occupational Rehabilitation, 21, 526-536. doi:10.1007/s10926-011-9302-8

Kayess, R., \& French, P. (2008). Out of darkness into light? Introducing the convention on the rights of persons with disabilities. Human Rights Law Review, 8(1), 1-34. doi:10.1093/hrlr/ngm044

Lawson, A., \& Priestley, M. (2017). The social model of disability: Questions for law and legal scholarship? In P. Blanck \& E. Flynn (Eds.), Routledge handbook of disability law and human rights (pp. 3-15). London: Routledge.

Mahoney, J., \& Goertz, G. (2006). A tale of two cultures: Contrasting quantitative and qualitative research. Political Analysis, 14, 227-249. doi:10.1093/pan/ mpj017

Mandal, R., \& Ose, S. O. (2015). Social responsibility at company level and inclusion of disabled persons: The case of Norway. Scandinavian Journal of Disability Research, 17(2), 167-187. doi:10.1080/ 15017419.2013.814586

McDowell, C., \& Fossey, E. (2015). Workplace accommodations for people with mental illness: A scoping review. Journal of Occupational Rehabilitation, 25, 197-206. doi:10.1007/s10926-014-9512-y

Moody, L., Saunders, J., Leber, M., Wojcik-Augustyniak, M., Marek, S., \& Rebernik, N. (2016). An exploratory study of barriers to inclusion in the European workplace. Disability and Rehabilitation, 39(20), 2047-2054. doi:10.1080/09638288.2016.1217072

Morgan, R., \& Melina, A. (2005). The Employer's perception: Employment of individuals with disabilities. Journal of Vocational Rehabilitation, 23(1), 39-49.

Morse, J. M. (2003). Principles of mixed methods and multimethod research design. In A. Tashakkori \& C. Teddlie (Eds.), Handbook of mixed methods in social and behavioral research (pp. 189-208). Thousand Oaks, CA: SAGE.

Nevala, N., Pehkonen, I., Koskela, I., Ruusuvuori, J., \& Anttila, H. (2015). Workplace accommodation among persons with disabilities: A systematic review of its effectiveness and barriers or facilitators. Journal of Occupational Rehabilitation, 25, 432-448. doi:10.1007/s10926-014-9548-z
OECD. (2003). Transforming disability into ability: Policies to promote work and income security for disabled people. Paris: OECD.

OECD. (2017). Employment outlook. Paris: OECD.

Olsen, T., Svendal, A., \& Amundsen, I. (2005). More inclusive workplaces: Fact or fiction? The case of Norway. International Review of Psychiatry, 17(5), 375-384. doi:10.1080/09540260500238579

Ose, S. O., Brattlid, I., \& Slettebak, R. (2013). 12 år med IA avtaler: Hva nå? [12 years with IA Agreement: What is now?]. Trondheim: SINTEF.

Padkapayeva, K., Posen, A., Yazdani, A., Buettgen, A., Mahood, Q., \& Tompa, E. (2016). Workplace accommodations for persons with physical disabilities: Evidence synthesis of the peer-reviewed literature. Disability and Rehabilitation, 39(21), 2134-2147. doi:10.1080/09638288.2016.1224276

Sandler, L. A., \& Blanck, P. (2005). The quest to make accessibility a corporate article of faith at microsoft: Case study of corporate culture and human resource dimensions. Behavioural Sciences and Law, 23, 39-64.

Schartz, H. A., Hendricks, D. J., \& Blanck, P. (2006). Workplace accommodations: Evidence based outcomes. Work, 27, 345-354.

Schur, L., Nishii, L., Adya, M., Kruse, D., Bruyère, S. M., \& Blanck, P. (2014). Accommodating employees with and without disabilities. Human Resource Management, 53(4), 593-621. doi:10.1002/hrm.21607

SSB. (2016). Statistics Norway: Disabled people, labour force survey. Statistics Norway. Retrieved from https://www.ssb.no/en/arbeid-og-lonn/statistikker/ akutu/aar/2016-09-02; https://www.ssb.no/en/virk somheter-foretak-og-regnskap/statistikker/utfono

Strand, V. B. (2014). Norway's ratification of the UN convention on the rights of persons with disabilities: Highlighting current discourses in the field of human rights in Norway. Nordic Journal of Human Rights, 32(1), 75-83. doi:10.1080/18918131.2013.878894

Svalund, J., \& Hansen, I. L. S. (2013). Inkludering av personer med nedsatt funksjonsevne $i$ arbeidslivet [Including persons with disabilities in working life]. Oslo: Fafo.

Tøssebro, J. (2004). Introduction to the special issue: Understanding disability. Scandinavian Journal of Disability Research, 6(1), 3-7.

Tøssebro, J. (2016). Scandinavian disability policy: From deinstitutionalisation to non-discrimination and beyond. ALTER: European Journal of Disability Research, 10, 111-123.

Vedeler, J. S. (2014). Disabled persons' job interview experiences: Stories of discrimination, uncertainty and recognition. Disability \& Society, 29(4), 597-610. doi:10.1080/09687599.2013.831748

Vedeler, J. S., \& Schreuer, N. (2011). Policy in action: Stories on the workplace accommodation process. Journal of Disability Policy Studies, 22(95). doi:10.1177/1044207310395942 
Vornholt, K., Uitdewilligen, S., \& Nijhuis, F. J. N. (2013). Factors accecting the acceptance of people with disabilities at work: A literature review. Journal of Occupational Rehabilitation, 23, 463-475.

Waddington, L. (2008). When it is reasonable for European to be confused: Understanding when a disability accommodation is "reasonable" from a comparative perspective. Comparative Labor Law \& Policy Journal, 29(3), 217-341.

Waddington, L. (2013). Reasonable accommodation be- yond disability in Europe? (D. G. f. Justice, Trans.). Luxembourg: European Commission.

Yin, R. (2009). Case study research. design and methods (4th ed.). London: SAGE.

Zissi, A., Rontos, C., Papageorgiou, D., Pierrakou, C., \& Chtouris, S. (2007). Greek employers' attitudes to employing people with disabilities: Effects of the type of disability. Scandinavian Journal of Disability Research, 9(1), 14-25. doi:10.1080/ 15017410600973234

\section{About the Authors}

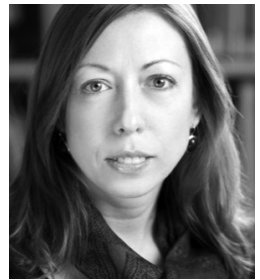

Yuliya Kuznetsova is a PhD student at NTNU, Department of Social Work, Trondheim, Norway. Since 2015, she has been working as a research assistant for Disability and Human Rights Observatory (ODDH) at the University of Lisbon, ISCSP, Portugal. Throughout 2011-2014 she had been employed as an Early Stage Researcher at NOVA (Norwegian Social Research Institute, Oslo, Norway) under the project Disability Rights Expanding Accessible Markets (DREAM), ID: 265057, stemming from the EU Marie Curie Initial Training Network Funding Programme.

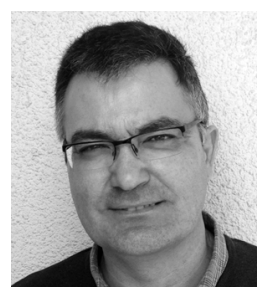

João Paulo Cerdeira Bento is a Lecturer in Economics and a member of the Research Unit on Governance, Competitiveness and Public Policy (GOVCOPP) at the University of Aveiro, Portugal. He received his PhD in Economics from the University of Reading, United Kingdom. His research interests include economics and international business. He is an invited Lecturer at Green Energy Management School (GEM), Department of Statistics and Quantitative Methods, University of Milano-Bicocca, Italy. 